\title{
E-collaboration: A Universal Key to Solve Fierce Competition in Tourism Industry?
}

\author{
Caiwei Ma \\ Economy \& Management Department, Tianhua College of Shanghai Normal University \\ No. 1661 North Shengxing Rd, Jiading District \\ Shanghai 201815, China
}

Tel: 86-21-3996-6301Ｅ-mail: macaiwei@yahoo.com.cn

\begin{abstract}
E-collaboration is a new strategy to compete in today's business world. Cooperation, collaboration, alliance and etc are the words companies are now focusing on. These companies are looking towards friendliness instead of hostility. This paper analyzes the previous literature on Internet, e-business, and collaboration, looking at the emergency of e-collaboration in the tourism industry. The applications of e-collaboration are often mentioned in the fields of international trading and e-business. The paper aims to apply those theories of collaboration, internet and e-business from other industries to tourism and hospitality industry. It also analyzes the e-collaboration situation in this particular area and tries to find a way to help today's tourism industry players to create and guide thriving e-collaboration strategies. E-collaboration provides a very efficient strategic option with low cost, easy access, large market, reputation and resources sharing. It brings geographically dispersed teams together, supporting communication, coordination and cooperation. But problems like unbalanced management and power between collaborators, unequal resource commitments, quality maintenance, culture differences exist in e-collaboration. In the end of the paper, the author highlights the advantages of e-collaboration and suggests the way to e-collaborate properly to contribute to strategic management.
\end{abstract}

Keywords: E-collaboration, E-business, Internet, Tourism

\section{Introduction}

The development of Internet technology and the dramatic spread of its use throughout the world in the past decade brought business into a new stage, a stage known 'e-time'.

Before ' $\mathrm{e}$ ' time, tourism industry players mainly maintained workable vertical relationships with its suppliers and their sales force (Appleman \& Go 2002). The walls of each company's office were not just physical bricks; they were also the spiritual boundaries isolating the company from its horizontal neighbours who do similar business. While drivers in the business environment such as globalization, regionalization, information technology and e-commerce decreased barrier effect of brick walls (Timothy 2003). Consumers are becoming more experienced. Competition between organisations by throwing bricks to each other can no longer lead to success (Stern \& Hicks 2000).

This article starts with relevant definitions of e-collaboration and the description of the change in the business environment and then analyzes these motivations, advantages and the problems of e-collaboration in the tourism industry. Multinatinational enterprise (MNE) and small business/tourism organisations are tending to adapt e-collaborative strategies. Gartner (2001) predicts that $70 \%$ of firms will have a coherent e-business strategy within a year. However, this is not a universal key if being used improperly. Addressing the theories of collaboration and e-business in other industries and trying to find a way of applying them to today's tourism industry players to create and guide thriving e-collaboration strategies is the main aim of this article.

E-collaboration bridges national borders and continents. E-collaboration and collaborative systems bring geographically dispersed teams together, supporting communication, coordination and cooperation. Indeed, it has become a cornerstone of global competition (Doz \& Hamel 1998; Timothy 2003). It is a logical and timely response to the quick change in the economic and IT world and split organizations into two competition divisions: one for the global market, one for the future development.

\section{Relevant definitions}

\section{E-business}

This field of activity is relatively young and evolving rapidly, and as such no single definition of the term has become 
accepted as the universal norm (Clegg et al 2001). E-business was initially limited to the financial transactions online. It was coined with a meaning of conducting business on the Internet by IBM back in 1997 as part of an advertising campaign. For the purposes of this essay, both business-to-business (B2B) and business-to-consumer (B2C) transactions and relationships are considered. Thus, e-business here is defined as the transaction of commercial activities on global open networks between an ever-increasing number of corporate and individual participants (Richmond et al. 1998).

\section{Collaboration}

According to Cambridge Advanced Learner's Dictionary (2003), collaboration means working jointly with others or together for some purpose or achieve the same thing. Words like strategic alliance, collaborative partnership, collaborative form, collaboration, partnership, and coalition are interchangeable utilized ( Fyall \& Spyriadis 2003).

E-collaboration is an extension from the old collaboration type in e-age. It is Internet-based cooperation/collaboration with exchange of information, materials, or cash among entities (Brown \& Sappenfield 2003).

\section{The changing of the business environment}

Information is the "lifeblood" of tourism. Since the tourism products can not be pre-tested, the access to accurate, timely and relevant information is therefore essential to consumers. Before the spread of Internet, telephone, fax, letter and face-to-face meeting were the main communication channels between suppliers and buyers. The generation, gathering, processing, application and communication of information was time consuming (O'Connor et al 2002). Consumers almost completely relied on representation and description to make an appropriate choice (Go and Pine 1995). Intermediaries played a very important role between disciplines and end-customers. Collaborations between horizontal tourism players were very rare.

While technology can act as a 'creator, enhancer, focal point and/or destroyer of the tourism experience' as O'Connor (2002 p332) indicated, the development of IT brought the business world a revolution of electronic. Business-related "dot-com" Web sites emerged all over the virtual world. A matching between buyer and seller was set up. Andy Grove, the chairman of Intel, predicted in 1999 that, within five years, all companies will be Internet companies or they will not exist.

As web-based technologies expanded, core back-office processes, including order management, procurement, logistics, financial management, and supply chain planning was incorporated (Gould 2004). The barriers and distance competitors were reduced. Information flows among the client, intermediaries and each of the suppliers involved in serving the client's needs. New relationships with customers, new relationships between competitors and suppliers and buyers, new business process, new information and communications technologies came into being and empowered employees are required (E-business Management Consultants 2003; Timothy 2003).

\section{Motivations for Collaboration}

Globalisation and regionalisation are emerging worldwide. This macro environment stimulates the development of IT; and the development of IT enhances the integration inversely. Hastings (1993) states that the need for 'quality, as well as the high costs and complexity of servicing global markets' is forcing organisations into collaborating with their clients, their suppliers and with their competitors in many new ways.

The power of IT allows information to be managed more effectively, and transported worldwide almost instantly (Frew and Pringle 1995). The physical boundaries between brick walls or territories can't block the information flow. Smaller countries, organisations, in particular, can benefit by gaining access to a much larger market than that in their own territories; large economic regions become available to them for sale of their goods and services (Timothy 2003).

From horizontal view, market is limited, the more ratio one company occupies, the less other companies occupies. But competitors in well-matched strength always exist. It's time for antagonists to begin to use the bricks to build something useful instead of throwing bricks at one another (Stern \& Hicks 2000). Collaboration offers a way to pursue business development, revenue increase, cost reductions in promotions and marketing and enhance market image and reputation (Fyall \& Spyriadis 2003). A partnership of collaboration is a tailored business relationship based on mutual trust, openness, shared risk and shared rewards that yields a competitive advantage, resulting in business performance greater than would be achieved by the firms individually (Lambert et al 1996; Cooper 1993; Oliver 1990).

In an executive report, META pointed that by 2001/02, high-performing enterprises will recognize the value of business collaboration to achieve flexibility, speed, and agility. By 2004, more than $30 \%$ of G2000 companies will have developed a collaborative competency and will use collaborative tools to extract superior value from their collaborative efforts (Passori 2000).

\section{Types of collaboration}

There are three types of collaboration: vertical relationships, horizontal relationships and diagonal relationships. (Fyall \& Spyriadis 2003) This is a classifying according to the different structure of collaboration and could suit 
e-collaboration.

\subsection{Vertical relationship}

Vertical relationship is the collaboration between suppliers and buyers e.g. travel operator and travel agency, travel agency and hotel. There is growing emphasis in modern supply chain literature on the importance of forming collaborative strategic partnerships with select trading partners (Kolluru \& Meredith 2001). The official site of Scotland's tourism board is one example. The links to travel agencies which sales its products can be found in this website. It offers you the service of journey booking while not owning a travel agency itself.

\subsection{Horizontal relationship}

Horizontal relationship is the collaboration between competing companies selling similar products or services, e.g. hotel and hotel (Bernal et al 2002). In tourism industry, horizontal collaboration happens more often than other two types with the spread of IT. This collaboration can be either inter-organisational which refers to licensing, franchising, sub-contracting and etc under one brand or alliance between different brands. Whichever horizontal collaboration the tourism industry players join, they are separated organisations by law (Fyall \& Spyriadis 2003; Stern \& Hicks 2000; Timothy 2003). Orbitz.com, for instance, was initially started by five airlines - American, Continental, Delta, Northwest and United to serve customers better and only sell flight tickets of these five owners. To gain more "click", it encourages other airlines to sell their tickets through its website. At the same time, other airlines are seeking for multi-distribution channels to explore market. Now Orbitz's inventory has hundreds of choices of airlines for customers. Marriott International has just signed a deal with Hotels.com. As part of the agreement, Marriott will have a direct link to the websites from its own central reservation systems. It will make its inventory of hotel rooms available to the sites. (Hotel Report 2003)

\subsection{Diagonal relationship}

Diagonal relationship is the relation where companies in different industries and sectors are working jointly. It's a dynamic structure and is growing follow closely to the other two types of e-collaboration (Brenner 2004). Grandheritage.com can illustrate this type of collaboration. Grandheritage.com is an online hotel booking website, but it has collaboration with Currency Converter, BBC Weather, Multi Map, British Tourist Authority (a site for events \& general information), British Airports Authority, London Transport, UK Genealogy (a site for tracing UK ancestry), Festivals.com(festivals and events in Europe), BITOA(The British Incoming Tour Operators Association), www.wellwellwell.co.uk(suppliers of water to hotels), and www.holidayautos.co.uk (low cost car hire). The collaboration is not just limited to the vertical supplier and buyer's relationship and horizontal relationship with competitors, but extends to other industries.

\section{The Influence of e-collaboration}

\subsection{Advantages}

6.1.1 Wider market and better competitive position.

Collaborative partners share common reservation system and customer databases. In this way tourism destinations, hotels, travel agencies and etc. can access to worldwide markets despite of the territory boundaries (Fyall \& Spyriadis 2003). The collaborated members can market as a whole sometimes (Teye 2000). Hospitality industry is witnessing the growth of technology-based collaboration best. An example of this is the Hilton International (UK based unit of Ladbroke Plc.) and Hilton Hotel Corporation (US based) alliance. These companies have entered into a relationship that involves sharing customer databases throughout the world. According to Hilton, the objective of this collaboration is to grow the brand to be able to compete on a global basis. Hotels.com is another good example for global market. It is one of the fastest growing hotel booking sites on the Internet. It offers savings of up to $70 \%$ off regular hotel rates in some of the world's most popular and expensive cities. What's more, the collaboration of the hotels guarantees traveler a room when cities are sold out. As Bruce Wolff, Marriott's senior vice president of sales and e-commerce strategy, said on Marriott's collaboration with expedia and hotel.com:' We want to ensure the travelers have access to Marriott properties no matter how they prefer to plan and book travel.'

This advantage is especially helpful to small and medium size tourism industry players. Collaboration through Internet enables them to source components and raw materials so as to widen their market and reputation (Gani 2001). E-collaboration offers the opportunity for companies to increase the numbers of potential suppliers, and for smaller companies to reach a larger trans-national client base (Leadbetter 1999)

'Through a close collaboration between hotels, restaurants, tourism and commerce, we can cater for anyone who wants to arrange their meeting or conference in Kristianstad or the surrounding area,' says Gunnel Ahlbeck of Turism Kristianstad (2003). When cross-border collaboration and cooperation in tourism promotion are formed, the global competitive advantage is likely to increase (Timothy 2003). 


\subsubsection{Value creation.}

Collaboration between competing firms may create favourable conditions for "inter-partner" learning (Dussage et al. 1999), allowing one firm to acquire capabilities that they lack from a partner, particularly when partners from different geographic region. Each partner will bring its product markets, technology, and experience to the collaborated group. A high-speed search and accurate results can be offered to customers with the sharing resources contributed by collaborators (O'Connor et al 2002). This caters for the increasing business-to-business or business-to-consumer demands for products and services with a wider resource of combination of each partner's limited resource.

What's more, value creation and its role in business network relationships is becoming an area of increasing interest (Blankenburg-Holm et al. 1998 in Bernal 2002) and enables firms to focus on combining internal and external resources in innovative ways.

\subsubsection{Inventories reduction.}

The closer, long-term, collaborative buyer-supplier relationships, i.e. partnerships, are enabled through seamless integration and transfer of information up and down the chain (Kolluru \& Meredith 2001). Strategic SCM can lower inventory risks and costs, improve customer service and satisfaction, increase customer retention and more effective marketing. (Horvath 2000) As distributors enter the same web, data on sales and inventories are received; forecasts are much easier to be made. With the forecasting and planning ability's improvement, collaborators will get benefit to know what to do next clearly. For example, Depkon's Hilton properties use a software application called Birch Street that manages the procurement and inventory at the property level. It allows the properties real-time access to suppliers' inventory. The sound e-collaboration makes the hotel managers focus on the day-to-day issues more and saves the hotel 8 percent to 15 percent (Higley 2004).

\subsubsection{Better communication.}

E-collaboration enhances inter-organizational relationships (O'Connor and Galvin 1998; Guide to the Use of Information Technology in the Supply Chain 1999; Song 1999). Though reduction in face-to-face contact and an increase in the opportunities for dispersed or paperless offices and people-less factories that have proved to be largely unfounded (Clegg et al 2001), e-collaboration does allow managers/staff to share information dynamically and far more quickly than previously. It enhances the gain from face to face meetings and other types of communication.

\subsubsection{Fewer cultural conflicts.}

As more collaborations are made, defining company culture is critical, especially when companies come from different countries. The social cultural environment will impact the company. While e-collaboration is based online, whether to customers or managers, it is more virtual than physical. Communicating while not working and meeting face to face day to day. Emotion and behavior interference will be less (Stern \& Hicks 2000).

\subsection{Key Problems}

Collaboration offers a way out of the fierce competition but it is not a universal key. Without good understanding and preparation, e-collaboration can also damage business. Not all collaboration or alliances or cooperation are successful. America's Tribune newspaper (2003) has reported a trend of hotel operators breaking away from their franchises and going it alone without big brand backing. The following are several key problems exist in e-collaborative relationship.

\subsubsection{Unequal resource commitments}

Perhaps the most critical thing in collaboration is the degree to which the partners' contributions are committed and complementary (Stern \& Hicks2000). Timothy (2000) pointed that the commitment on the part of individual nations to giving up absolute control in some areas is lack, because national interests nearly always outweigh cross-national interests when he talked out the collaboration between countries. It is a common problem throughout the world where collaboration is being undertaken no matter it is a horizontal collaboration, vertical collaboration or diagonal one.

\subsubsection{Unbalanced management and power}

Unbalanced management and power results from unequal commitment. But no party wants to be at a disadvantage in cooperation. The unbalanced situation sometimes leads to inefficient if dealt wrong.

\subsubsection{Different maintenance of quality standards between partners}

Every tourism industry player has different internal needs for different technological and organizational systems and external needs for connectivity and share-ability of messages, data, applications and processes (Stern \& Hicks 2000). But once collaborated, the reputation and services of each collaborator are bounded together. One comparatively worse website or service will lead to the poor impression of the whole group to customer. And also because of the collaboration of huge database, the difficulty of maintenance is increasing (Bernel et al 2002). 


\subsubsection{Losing the opportunity for a creative solution}

Problems are sometimes unavoidable no matter what product and what life stage. When an enterprise meets conflicts or problems entering a market, it might find its own way to solve itself. E-collaboration may need certain managers to negotiate with those who have been in the market and link their websites and database to bridge the markets.

\section{Suggestions and conclusions}

E-collaboration is a very vital strategy for tourism industry players in today's business world. Vertical and horizontal e-collaboration is more often to see in tourism industry than diagonal collaboration. But this type of e-collaboration will be a trend when vertical and horizontal collaboration have developed well. Cooperation between different industries will enhance each other and help each industry's development.

Smartly using this strategy can avoid the fierce competition between hotels, travel agencies and travel operators. As discussed above, e-collaboration can help to widen market, enhance competitive position, add value, reduce cost, bridge communication and lessen cultural conflicts. It is a great strategy more SME to compete with stronger competitors. But Zaid Ismail (2003), senior director of the National Chamber of Commerce and Industry of Malaysia (NCCIM), said though many small and medium size companies have their own websites, not all of them are aware of the benefits of e-business and fully utilize this tool.

Either to small business/tourism organisations or multinational enterprise, to take successful e-collaboration strategy to compete in the global market, the following suggestions should be considered:

- Choose your partner carefully. Every enterprise should know clearly its own strengths and weaknesses before collaborating, and then smartly look for partners that can fit its wants.

- Necessary information technology. The information that an organization communicates with its supply chain partners is among the most critical of its assets. Powerful, integrated collaborative technology is the backbone of an e-collaboration (Vlachopoulou and Manthou 2003). Protection must be provided against external threats and from internal abuse (Kolluru \& Meredith 2001). The data that is shared between the partners and customers engaged in these different types of relationships varies widely in its criticality, thus requiring different levels of security.

- Managing the balance of power and dependence. Normally a partner who brings differentiating contributions of a more sustainable nature --- such as a leading brand--- will enjoy a more sustained influence. And the smaller partner is comparably more dependent. The dependence comes from commitments. As the commitments are irreversible, more specific commitments should be done so that every partner is very clear about its role and contribution, for example, the service standard, price, credit policy, service level performance, response time, image and etc. The trust between partners should be well set up as the basis of enduring collaborative relationships (Donington 1995, Richmond et al. 1998).

- Monitoring the quality. Quality is the life core in any industry. Service, price, credit policy, response time, and legal issue warranties and so on detailed things should also be considered carefully. Online service and face-to-face service should be both monitored. Keeping a sustainable good quality can enhance customer's loyalty and then raise the company's reputation.

- Hiring intelligent and empowered employees. Managing e-collaboration will be more difficult than traditional management activities, as the systems become potentially more complex, more tightly coupled, and increasingly involve complex interrelations between people, organizations and technology (Timothy 2003). Companies need more than just good technology to make the most of the Internet (Cairncross 2000).

Evaluation can also not be forgotten while using e-collaboration strategy. Individually, jointly and publicly evaluation all are important to keep the process on its way to success.

This paper addresses the relevant theories on e-business and internet to the specific tourism industry. But as time and resources are limited, no particular case study is offered to support the researcher's ideas. E-trading is the industry witnesses the technology information development first and reacts first. The theories and practice in this industry can be studied more to contribute to tourism. A further research of comparing and analyzing the similarities and differences between these two industries, especially the e-market place and online travel agencies can be carried out. What's more, the research of the trend of diagonal e-collaboration in tourism industry is also worth researching.

\section{References}

Allisat, B. (2004). At a drop of hat (the definition of internet).(online)Available: http://www.gtld-mou.org/gtld-discuss/mail-archive/05134.html (Feb,2004).

Appleman,J. \& Go,F. (2002).Transforming Relationships Between Airlines and Travel Agencies: Challenges for Distribution and the Regulatory Framework. Tourism Distribution Channels: Practices, Issues and Transformations. London: Continuum. 
Bafoutsou,G. \& Mentzas,G. (2002).Review and functional classification of collaborative systems. International Journal of Information Management. 22;4, pp. 281-305.

Bernal,S.,Burr, C. \&Johnsen, R. (2002).Competitor networks: international competitiveness through collaboration: The case of small freight forwarders in the High-Tech Forwarder Network. International Journal of Entrepreneurial Behaviour and Research. 8;5, pp. 239-253.

Brenner, B. (2004). Diagonal Collaborations: Dazzling or Dangerous? Chaco Canyon Consulting.(online)Available:http://www.chacocanyon.com/pointlookout/010516.shtml (April,2004).

Brown, M. \& Sappenfield, D. (2003). Collaborative. (online)Available:Http://www.intelligentententerprise.com (Feb,2004).

Buhalis, D. \& Laws, E. (2002). Tourism Distribution Channels: Practices, Issues and Transformations. London: Continuum.

Chathoth, P. \& Olsen, M. (2003). Strategic Alliances: A Hospitality Industry Perspective. Hospitality Management. 22; 4, pp.419- 434.

Clegg, C. W. , Icasati-Johanson, B. \& Bennett,S. (2001). E-business: boom or gloom?Behaviour and Information Technology. 20;4, pp. 293-298.

Donington,J. (1995). Electronic Data Interchange in the Automotive Industry: Managing Information Flows for Greater Profitability. Financial Times Management Reports. London: Pearson Professional Ltd.

Doz,Y. \& Hamel,G. (1998). Alliance advantage: the art of creating value through partnering. Boston: Harvard Business School Press.

Dussage,P., Garrete,B., \& Mitchel,W. (1999). Learning from competing partners: outcomes and durations of scale and link alliances in Europe, North America and Asia. Strategic Management Journal.24;3, pp.231-242.

E-business Management Consultants. (online) Available: Http://www.quickredfox.co.uk/ebusiness-explained.htm (Feb, 2007).

Frew, A. \& Pringle, S. (1995). Multi-media Marketing Across ATM Broadband Networks - A Hospitality and tourism Perspective: Part One. The Hospitality Information Technology Association Worldwide Conference.

Fyall, A. \& Spyriadis, A. (2003). Collaborating for Growth: the International Hotel Industry. Journal of Hospitality and Tourism Management. 10;2, pp. 108-123.

Gani,H. (2001). Enhancing Product Quality. New Straits Times. Malaysia. 26July 2001.

Go,F. \& Pine, R. (1995). Gobalisation Strategy in the Hotel Industry. New Yourk: Routledge.

Gould, L. (2004). What's in an Online Marketplace? (online) Available:Http://www.autofieldguide.com (Feb,2004).

Guide to the Use of Information Technology in the Supply Chain: Making Technology Pay. (1999). London: Price Waterhouse Coopers.

Horvath, L. (2001). Collaboration: the key to value creation in supply chain management.

Supply Chain Management: An International Journal. 6; 5, pp. 205-207.

Higley, J. (2004). Supply-chain Policies Help Hoteliers Save Time, Mondy. Hotel \& Motel Management. 219; 3, pp. 26-27.

IBM and E-collaboration. IBM.com. (online)Available:http://www-5.ibm.com/e-business/pl/e-collaboration/intro/ (Feb,2007).

Independence Day for Franchise Operators. (2003). Hotel Report. 6;12,pp.1.

Jaquith, A. (2002). Securiting Avallable:

Http://www.stake.com/research/reports/acrobat/atstake_securing_ecollabor...(Feb,2004).

Knudsen, D. \& Sweden, L. (2003). Aligning corporate strategy, procurement strategy and e-procurement tools. International Journal of Physical Distribution\& Logistics Management. 33;8, pp.720-734.

Kolluru, R. \& Meredith, P. H. (2001).Security and trust management in supply chains. Information Management \& Computer Security. 9;5, pp. 233-236.

Le, T. (2002). Pathways to Leadership for Business-to-Business Electronic Marketplaces. Electronic Markets. 12;2, pp.112.

Leadbetter, C. (1999). Living on Thin Air. London: Penguin.

Marriott Joins third Party sites for Online Management. (2003). Hotel Report. 6;12, pp. 6. 
O’Connor, P., Buhalis, D. \& Frew, A.J. (2002). The Transformation of Tourism Distribution Channels Through Informaion Technology. Tourism Distribution Channels: Practices, Issues and Transformations. London: Continuum.

O’Connor, J. \& Galvin, E. (1998). Creating Value through eCommerce. Management Briefings: General Management. London: Financial Times Management.

Oz, E. (2002). Foundations of E-commerce.U.S.A.: Prentice Hall.

Passori, A. (2000). Executive Direction. Stamford: META Group In.

Richmond, C., Power, T. \& O'Sullivan, D. (1998). E-business in the Supply Chain: Creating Value in a Networked Marketplace. London: IBM.

Song, S. (2004). Guidelines on the Use of Electronic Networking to Facilitate Regional or Global Research Network. (online) Available:Http://www.idrc.ca/books/focus/890/15aSong.html (Feb,2007).

Stern, A. \& Hicks, T. (2000). The Process of Business/ Environmental Collaborations. USA: Quorum Books.

Timothy, D. J. (2003). Supranationalist Alliances and Tourism:Insights from ASEAN and SAARC. Current Issues in Tourism. 6;3, pp. 250-167.

Tourism collaboration and partnerships: politics, practice, and sustainability. (2000). Clevedon: Channel View.

Trends \& Indicators: Collaboration. (2002). Business Intelligence Market Watch. 13; 2, pp. 28.

Vlachopoulou, M. \& Manthou, V. (2003). Partnership alliances in virtual markets.

International Journal of PhysicalDistribution \& Logistics Management. 33; 3, pp.254-267. 